EESTI NSV TEADUSTE AKADEEMIA TOIMETISED. 19. KOIDE

KEEMIA * GEOLOOGIA. 1970, Nr. 4

ИЗВЕСТИЯ АҚАДЕМИИ НАУК ЭСТОНСКОИ ССР. ТОМ 19

Химия * ГЕОЛОГИя. 1970 , ㅊ․ 4

И. КЛЕСМЕНТ, ЮТА РИККЕН, О. ЭИЗЕН, Ю. ХАМАРНЕХ

\title{
СОСТАВ СМОЛЫ ГОРЮЧЕГО СЛАНЦА ИОРДАНИИ
}

Сланцы - низкосортное, многозольное топливо, залежи которых мсжно встретить почти во всех странах мира. Состав их органической и минеральной части разнообразен. Изучив состав смолы, получаемой при полукоксовании сланца, получим данные для ее практического использования, а также информацию о структуре и условиях генезиса керогена.

Минеральная часть сланцев Иордании характеризуется высоким содержанием карбонатов, а органическая - высоким содержанием серы. В СССР в таком количестве серу содержат сланцы Общего Сырта и Кашпира. Данные о составе сланцев Общего Сырта и Иордании, а также результаты настоящей работы приведены в табл. 1.

Таблица 1

\section{Сравнительная характеристика сланцев} Иордании и Общего Сырта

\begin{tabular}{c|c|c}
\hline Показатель & $\begin{array}{c}\text { Сланец } \\
\text { Иордании }\end{array}$ & $\begin{array}{c}\text { Оланец } \\
\text { Сбего } \\
\text { Сырта [6] }\end{array}$ \\
\hline
\end{tabular}

Содержание органического вещества в сланце, \%

Элементарный состав органического веще. ства, \%

$24,3 \quad 35-48$

$\begin{array}{rrrr}\mathrm{C} & & 75,4 & 62,9 \\ \mathrm{H} & & 10,0 & 8,1 \\ \mathrm{~S} & & 7,0 & 7,3 \\ \mathrm{~N} & \mathrm{I} & 7,6 & 1,2 \\ \mathrm{O} & \mathrm{I} & & 20,5\end{array}$

Выход продуктов при полукоксовании из органического вещества, \%

смола

подсмольная вода газ + потери

Групповой состав смолы, \% парафины

олефины ароматические и сероорганические со. единения кислородные соединения

Удельный вес смолы

Элементарный состав смолы, \%

\section{4,7}

5,8

18,3

17,7

13,1

56,1

13,1

0,936

27,20

13,20

20,0

\section{4,0}

47,2

37,0

1,0

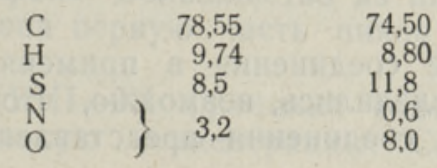


Полукоксование ниже 0,2 м.м измельченного сланца проводилось в лабораторной установке, которая уже раньше использовалась в этих целях [1]. Сланец в количестве 1,2 к2 находился в аппарате в виде тонкого слоя, что обеспечивало его равномерный подогрев и быстрое эвакуирование летучих продуктов. График повышения температуры был близок к стандартному режиму, используемому при опытах в алюминиевой реторте Фишера. Интенсивное разложение керогена проходило при температуре $300-450^{\circ} \mathrm{C}$, нагрев выключался при $550^{\circ}$. Швельгаз и полученная смола имели сильный запах сероводорода; иорданская сланцевая смола по сравнению с эстонской была светлее и вязкость ее выше.

Таблица 2

Характеристика фракций иорданской сланцевой смолы

\begin{tabular}{|c|c|c|c|c|c|}
\hline \multirow{2}{*}{ Показатель } & \multicolumn{5}{|c|}{$\Phi$ р а кц и и } \\
\hline & 1 & 2 & 3 & 4 & 5 \\
\hline Выход, вес. \% & 4.2 & 11,9 & 26,8 & 23,0 & 24,8 \\
\hline $\begin{array}{l}\text { T. кип., }{ }^{\circ} \mathrm{C} \text { при атмо- } \\
\text { сферном давлении }\end{array}$ & до 100 & $100-200$ & $200-300$ & $300-391$ & $391-445$ \\
\hline $\begin{array}{l}\text { Удельный вес } \\
\text { Показатель преломле- }\end{array}$ & 0,750 & 0,851 & 0,915 & 0,962 & 0,974 \\
\hline ния & 1,4300 & 1,4600 & 1,5020 & 1,5262 & 1,5472 \\
\hline Содержание серы, \% & 3,88 & 9,5 & 9,5 & 8,5 & 6,2 \\
\hline $\begin{array}{l}\text { Содержание кислоро- } \\
\text { да, \% }\end{array}$ & 0,66 & 0,88 & 1,26 & 1,46 & 1,66 \\
\hline
\end{tabular}

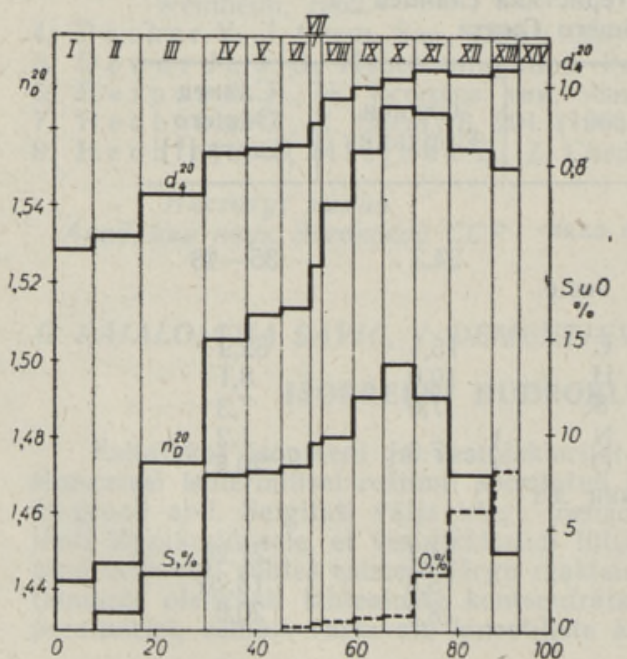

Рис. 1. Выход хроматографических фракций при разделении иорданской смолы в колонке на окиси алюминия и физикохнмические показатели полученных фракций. матические соединения в применяемых условиях хроматографирования не разделились, возможно, что количество последних небольшое. Сернистые соединения представлены двумя группами. Первая имеет 
Рис. 2. Хроматограммы исходной смолы и выделенных из нее групп:

I - исходная смола; $I I$ - фракция парафинов и олефинов, номера пиков на хроматограмме эзначают количество углеродных атомов в соедннениях; III - фракция сернистых соединений тиофенового и тнофанового характера: IV - фракция сернистых соединений полициклического характера; $V$ - фракция кислородных соединений.

Условня хроматографирования: колонка диамет ром $6 / 4$ м., длиной 6 м. $5 \%$ апиезона $L$ на хромосорбе $G$, расход водорода $75-40 \mathrm{M. \Omega} / \mathrm{Muн}$.

относительно низкий удельный вес и показатель преломления, а вторая - высокосернистая группа -более высокие показатели. В последних хроматографических фракциях серу заменяет кислород.

В дальнейшем каждая выделенная группа изучалась газохроматографически. Использовалась неполярная апиезоновая колонка, в которой соединения разделяются в основном по температуре кипения. Для анализа ширококипящих фракций температура колонки программировалась [2]. Хроматограммы исходной смолы и выделенных из нее групп, а также условия хроматографирования приводятся на рис. 2.

На хроматограмме исходной смолы видно множество пиков, выходящих из хроматографа по группам, которые имеют равные расстояния и разное число компонентов.

На хроматограмме парафинов и олефинов (фракции I-III) пики образуют два ряда: первый принадлежит нормальным олефинам, а второй - нормальным парафинам. В каждой паре компоненты имеют одинаковое количество углеродных атомов. В применяемых условиях хроматографирования пики обоих рядов в конце хроматограммы совпадают. Количество олефинов немного меньше, чем парафинов. Присутствуют нормальные соединения $\mathrm{C}_{7}-\mathrm{C}_{26}$.

На следующей хроматограмме представлены пики относительно слабоадсорбируемых сернистых соединений (IV-VII фракции). Здесь соединения также выходят по группам, компоненты каждой следующей группы имеют на один углеродный атом больше. В данном случае мы не мсжем установить, принадлежат соединения к гомологическим рядам (наличие прямолинейных цепей) или к разным структурным изомерам. Такие группы, которые имеют многочисленные пики могут образовать и алкилароматические соединения с близкими сорбционными свойствами [3]. По физико-химическим показателям соединения фракций IV-VII имеют структуру тиофена и тиофана. Большинство из них относительно низкокипящие и составляют они первую часть пиков хроматограммы исходной смолы.

Высокосернистая часть смолы (VIII-XI фракции) содержит нескөлько компонентов, имеющих -высокую концентрацию. Соединения 


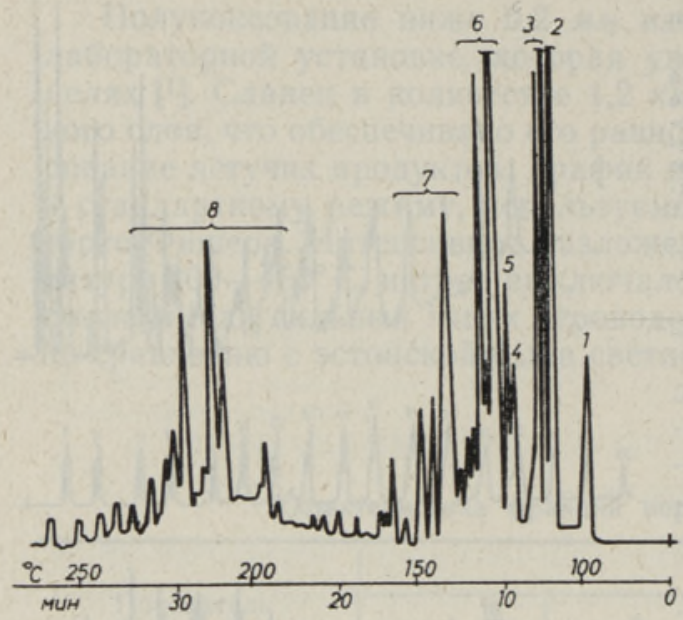

Рис. 3. Хроматограмма фенолов. Идентифици рованные компоненты:

1 - фенол, 2 - 2-метилфенол, 3 - 3- и 4-метилфенолы, 4 - 2,6-диметилфенол, 5 - 2-этилфенол, 6 алкилфенолы $\mathrm{C}_{8}, 7$ - алкилфенолы $\mathrm{C}_{9}, 8$ - нафтолы условия хроматографирования см. рнс. 2.

этой группы, по данным адсорбционной и газовой хроматографии, высококипящие, имеют полициклическую ароматическую структуру и содержат в молекуле более одного атома серы.

Последняя - сильноадсорбируемая группа, т. е. кислородные соединения (фракции XII-XIV) содержат еще довольно много сернистых соединений. В начале на их хроматограмме, как и на хроматограмме парафинов и олефинов, видны парные пики. По данным ранее проведенных исследований [ $\left.{ }^{4}\right]$, эти соединения являются нормальными кетонами; вторые пики представляют собой гомологический ряд нормальных 2-кетонов, остальные $\boldsymbol{H}$-изомеры присутствуют в первых пиках.

Смола содержит также небольшое количество $(1,2 \%)$ фенолов, которые представлены низкокипящими соединениями: фенолом, крезолами и ксиленолами, а содержание ортоизомеров низкое (рис. 3).

Как видно из табл. 1, смолу характеризует, кроме высокосернистости, гакже высокое содержание водорода. Последнее обусловлено присутствием в исходном керогене в большом количестве длинных углеродных цепей, которые являются характерной составляющей частыо керогенов многих сланцев [ $\left.{ }^{5,6}\right]$.

\section{ЛИТЕ РА Т У Р А}

Эй зе н О. Г., Р иккен Ю. Т., Изв. АН ЭССР, Физ. Матем., 16, 108 (1967).

К.лесмен т И. Р., Изв, АН ЭССР, Хим. Геол., 17, 285 (1968).

Клесмент И. Р., В ахесса ар В. А., Эйзен О. Г., Хнмия твердого топлива (в печати).

Касберг А. Ф., Клесмент И. Р., Химия твердого топлива, № 1, 107 (1969).

Клесмент И. Р., Касберг А. Ф., Салусте С. Я., Эйзен О. Г., Фомина А. С., Химия твердого топлива, № 2, 67 (1969).

Д об р я н ски й А. Ф., Горючие сланцы СССР, Л., 1947.

Институт химии

Академии наук Эстонской ССР
Поступила в редакцию 13/III 1970

\section{KLESMENT, JUTA RIKKEN, O. EISEN, J. HAMARNEHH}

\section{JORDAANIA POLEVKIVIOLI KEEMILINE KOOSTIS}

Laboratooriumis saadud õli kromatograafiline analüüs näitas, et ôli sisaldab üle $50 \%$ väävliühendeid. Kōrge on ka sirge ahelaga parafiinide ja olefiinide sisaldus. $n$-alküülketoone esineb vähesel hulgal. 
I. KLESMENT, JUTA RIKKEN, O. EISEN, J. HAMARNEHH

\section{ZUSAMMENSETZUNG DES JORDANISCHEN BRENNSCHIEFERTEERS}

Im Laboratorium angefertigtes Teer wurde mit chromatographischen Methoden untersucht. Der Teer enthält über $50 \%$ Schwefelverbindungen. Der Gehalt an Paraffinen und Olefinen mit gerader Kohlenstoffkette ist gleichfalls hoch. n-Alkylketone sind nur in geringer Menge vorhanden. 